\title{
TREND ANALYSIS, MODELLING AND IMPACT ASSESSMENT OF COVID-19 IN NEPAL
}

\author{
Shital Bhandary ${ }^{1}$, Srijan Lal Shrestha ${ }^{2}$, Ram Prasad Khatiwada ${ }^{2}$, Deep Narayan Shah ${ }^{3}$, Nabin Naraya \\ Munankarmi $^{4}$, Megha Raj Banjara ${ }^{5}$, Resham Thapa-Parajuli ${ }^{6}$, Krishna Das Manandhar ${ }^{7}$, Rameshwar Adhikari $^{8}$, \\ Reshma Tuladhar ${ }^{5^{*}}$ \\ ${ }^{I}$ School of Public Health, Patan Academy of Health Sciences, Lalitpur, Nepal \\ ${ }^{2}$ Central Department of Statistics, Tribhuvan University, Kathmandu, Nepal \\ ${ }^{3}$ Central Department of Environmental Science, Tribhuvan University, Kathmandu, Nepal \\ ${ }^{4}$ Biotechnology Society Nepal (BSN), Bhaktapur, Nepal \\ ${ }^{5}$ Central Department of Microbiology, Tribhuvan University, Kathmandu, Nepal \\ ${ }^{6}$ Central Department of Economics, Tribhuvan University, Kathmandu, Nepal \\ ${ }^{7}$ Central Department of Biotechnology, Tribhuvan University, Kathmandu, Nepal \\ ${ }^{8}$ Research Center for Applied Science and Technology, Tribhuvan University, Kathmandu, Nepal \\ "Corresponding author: reshma.tuladhar@cdmi.tu.edu.np
}

(Received: September 01, 2020; Revised: November 20, 2020; Accepted: November 21, 2020)

\begin{abstract}
With the continued global expansion of COVID-19 transmission and the mounting threat of the disease, the timely analysis of its trend in Nepal and forecasting the potential situation in the country has been deemed necessary. We analyzed the trend, modelling, and impact assessment of COVID-19 cases of Nepal from $23^{\text {rd }}$ January 2020 to $30^{\text {th }}$ April 2020 to portray the scenario of COVID-19 during the first phase of lockdown. Exponential smoothing state-space and autoregressive integrated moving average (ARIMA) models were constructed to forecast the cases. Susceptibleinfectious-recovered (SIR) model was fit to estimate the basic reproduction number (Ro) of COVID-19 in Nepal. There has been an increase in the number of cases but the overall growth in COVID-19 was not high. Statistical modelling has shown that COVID-19 cases may continue to increase exponentially in Nepal. The basic reproduction number in Nepal being maintained at a low level of 1.08 for the period of $23^{\text {rd }}$ January to $30^{\text {th }}$ April 2020 is an indication of the effectiveness of lockdown in containing the COVID-19 spread. The models further suggest that COVID-19 might persist until December 2020 with peak cases in August 2020. On the other hand, a basic reproduction number of 1.25 was computed for total cases reported for the $22^{\text {nd }}$ March to $30^{\text {th }}$ April 2020 period implying that COVID-19 may remain for at least a year in the country. Thus, maintaining social distance and stay home policy with an implementation of strict lockdown in the COVID-19 affected district is highly recommended.
\end{abstract}

Keywords: Autoregressive integrated moving average, COVID-19, Doubling time, Exponential smoothing, Susceptibleinfectious-recovered model

\section{INTRODUCTION}

The ongoing Corona Virus Disease 2019 (COVID-19) caused by novel Severe Acute Respiratory Syndrome Coronavirus 2 (SARS CoV-2) was reported to have emerged from Wuhan, Hubei, China in late December 2019, where people in a seafood-wholesale wet market suffered from a mysterious pneumonia (Wu et al., 2020). World Health Organization (WHO) declared the outbreak as public health emergency of international concern on $30^{\text {th }}$ January 2020, announced a new name for this disease as COVID-19 on $11^{\text {th }}$ February 2020 and pandemic on $11^{\text {th }}$ March 2020 (WHO, 2020b). With rapid spread in Europe, America, and Asia, COVID-19 was confirmed globally in $3,090,445$ people with 217,769 deaths by $30^{\text {th }}$ April 2020 (WHO, 2020a). The highest infection and death toll have been recorded in the USA followed by countries in Europe, Eastern Mediterranean, South-East Asia, Western Pacific, and least in Africa (WHO, 2020c).
The first case of COVID-19 in Nepal reported in a 32 years old Nepalese male who was admitted to the hospital upon exhibiting mild symptoms, later discharged on $17^{\text {th }}$ January 2020 after improvement in clinical condition was a returnee from Wuhan City on $9^{\text {th }}$ January 2020 (Bastola et al., 2020).

On $24^{\text {th }}$ January 2020 , the infection was officially confirmed COVID-19 after reported positive from WHO reference laboratory in Hong Kong (Bastola et al., 2020; MoHP, 2020). Later the second case was confirmed on $23^{\text {rd }}$ March 2020 in a 19 years old female who returned from France via Doha, Qatar (Pun et al., 2020). On 24 ${ }^{\text {th }}$ March 2020, the Government of Nepal implemented a nationwide lockdown advising residents to stay at home. Until $13^{\text {th }}$ April 2020, the cases in Nepal were reported from the people who recently returned from abroad, and Indian nationals residing in Nepal where the latter case was in majority. 
Trend analysis, modelling and impact assessment of COVIS-19 in Nepal

The first case of indigenous transmission confirmed on $4^{\text {th }}$ April 2020 in a 34-year-old woman from Kailali District was a relative of the infected patient who travelled from India (Pun et al., 2020). By the end of the first phase of lockdown of $28^{\text {th }}$ April 2020, 54 cases have been confirmed with documentation of no deaths (MoHP, 2020). COVID-19 has spread in 10 districts of Nepal with Udayapur reported the maximum number of 25 cases.

Considered as the standard laboratory test for the diagnosis of COVID-19 the cases were confirmed by Reverse Transcription Real-Time Polymerase Chain Reaction (RT-PCR) (Paudel et al., 2020; Yip, et al., 2020). Until $30^{\text {th }}$ April 2020, a total of 12,011 RT-PCR tests and 46860 Rapid Diagnostic Test (RDT) were performed in Nepal out of which 57 were tested positive. In consideration of numerous COVID-19 cases being detected in Nepal, it has been essential to let the Nepal Government be prepared for the most predictable upcoming situation to tackle the COVID-19 pandemic. This paper, therefore, assessed the descriptive and trend analysis on the growth of cases, its doubling time, statistical and epidemiological model.

\section{MATERIALS AND METHODS}

\section{Data sources}

The secondary data from the Ministry of Health and Population (MoHP, 2020), Nepal, Health Emergency Operation Centre, and data from relevant websites related to COVID-19 in Nepal were analyzed. Trend analysis was performed from daily compiled data of 102 days from the last week of January 2020 till the end of April 2020. Major variables associated with the disease; such as demographic variables of the cases, diagnostic tests including RT-PCR and RDT, number of cumulative and daily cases as well as that of recovered, quarantined, and isolated cases were considered. Additionally, analysis of important variables such as cases as percent of PCR tests, doubling time of COVID-19 cases for Nepal was weekly assessed and represented graphically. Finally, different time points were used to develop prediction models while impact assessments have been analyzed using the whole data.

\section{Statistical analysis: ETS and ARIMA models}

The exponential smoothing state-space method (which comprises 'Error, Trend, and Seasonal' components in smoothing procedure of an event under consideration; hence named ETS model) which takes information into comprehensive consideration and ARIMA model (Hyndman \& Athanasopoulos, 2018) were used to forecast COVID-19 cases for Nepal by fitting in $\mathrm{R}$ software using forecast package (Hyndman et al., 2020). We selected the best ETS model and best ARIMA model for 99 days official cumulative COVID-19 cases from $23^{\text {rd }}$ January to $30^{\text {th }}$ April 2020 and forecasted the cases for the next 14 days ( $1^{\text {st }}$ May $-14^{\text {th }}$ May 2020). An attempt has been made in the direction of epidemiological modelling through application of SIR model (see next section for detail) based upon the suitable parameter values for Nepal.

\section{Mathematical analysis: SIR model}

We used the SIR model, a compartmental model where the population is divided into three compartments: susceptible, infectious and recovered. We need two types of rates to move from one compartment to another viz. rate of transmission $(\beta)$ to move from Susceptible to Infectious compartment and rate of recovery $(\gamma)$ to move Infectious to Recovered compartment as follows:

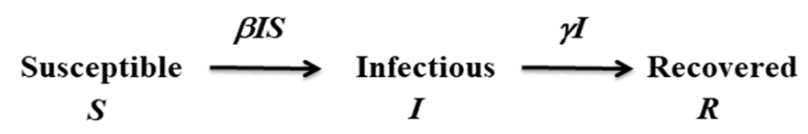

This type of model is a dynamic model as the population in these three compartments changes with each unit of time and this can be modelled using differential equations. The simple SIR model without vital dynamics i.e. births and deaths are modelled as follows:

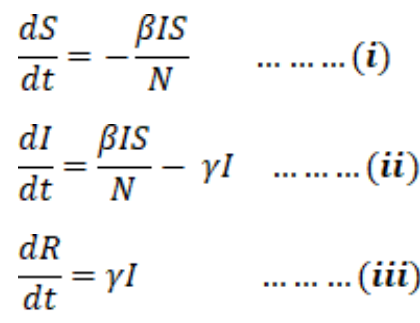

Where, S, I, and R were stock of susceptible, infected, and recovered population. Change in $S, I$, and $R$ with respect to time was computed with an initial value of $I=1$ and $R$ $=0$ to represent the first COVID-19 case of Nepal on $23^{\text {rd }}$ January 2020. S was taken as 29 million, which is the projected population of Nepal for April 2020. Two SIR models were fitted, first with basic reproduction number (Ro) of 2.5 (global average of COVID-19) and 1.0 (to make COVID-19 endemic) in Nepal.

To solve differential equations (i), (ii), and (iii), we used the Runge-Kutta method available in the "deSolve" package (Soetaert et al., 2010) in $\mathrm{R}$ software version 3.5.2. We also fitted the SIR model for the official COVID-19 cases between $23^{\text {rd }}$ January and $30^{\text {th }}$ April as well as between $22^{\text {nd }}$ March and $30^{\text {th }}$ April 2020 and computed Ro for these periods using the Limited Memory-Broyden-Fletcher-Goldfarb-Shanno (LM-BFGS) optimization algorithm in the $\mathrm{R}$ software. Since the second COVID-19 case was reported on $23^{\text {rd }}$ March 2020 , we also used a period between $22^{\text {nd }}$ March and $30^{\text {th }}$ April 2020 to check the effectiveness of the lockdown started from $24^{\text {th }}$ March 2020 in Nepal. We created the change in the infected compartment for Nepal using these Ro values 
and derived the time-based effect of COVID-19 cases for Nepal.

\section{RESULTS}

\section{Trend of the cases}

From $21^{\text {st }}$ January 2020 till $30^{\text {th }}$ of April 2020, a total of 57 COVID-19 cases have been confirmed in Nepal. The increase in case was slow with only ten cases recorded between $21^{\text {st }}$ March and $10^{\text {th }}$ April, 2020, but due to a sudden sharp rise in new cases in some days, the trend of daily new cases was found erratic and inconsistent. The growth curve of the total cases in Nepal resembles a logistic curve where the total numbers of cases and the curve for active COVID-19 persons have also risen similarly but a dip in active cases has been observed lately (Fig. 1). The number of recoveries has also risen significantly in the recent past two weeks which is a positive sign.

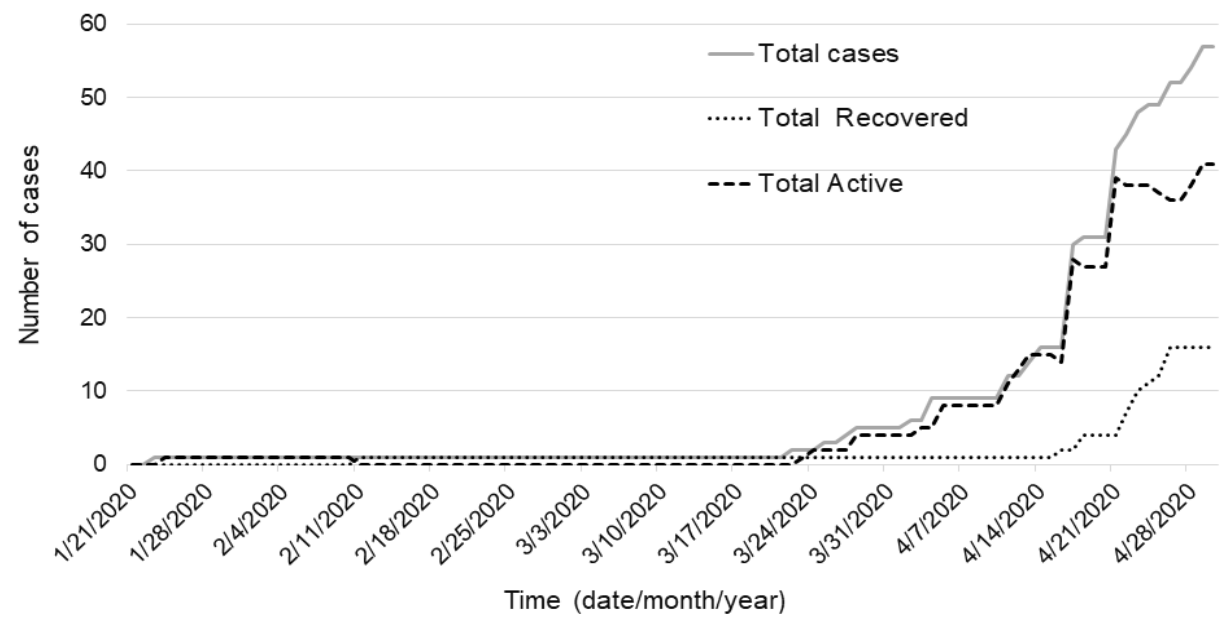

Fig. 1. Trend of active, recovered, and total number of COVD-19 cases with time

In Nepal, males with age between 21- 30 years are found more infected. The highest number of infected male populations may be related to the cases dominated by the male who lived in Bhulke, Triyuga Municipality, Udayapur district, and the person who came in contact with them. The majority of infected belong to the people who entered Nepal from India while some of the infected had a history of travel from other countries such as China, France, UAE, Belgium, UK, and Saudi Arabia (Pun et al., 2020). The percent of cases indicated by RT-PCR tests rapidly decreased as the number of tests increased in the month of February and has remained consistently low between 0.2 to $0.5 \%$ thereafter.

\section{Doubling time of COVID-19 cases in weekly data analysis}

Examination of doubling time of the COVID-19 cases in Nepal based upon weekly data analysis showed that there has been an increase in doubling time steadily starting around the third week of March till the second week of April from 3.5 to 14 days with a long period for doubling duration initially from one reported case to two. Thereafter, it dropped sharply followed by an unexpected sudden rise in the cases during the third week of April. After that, it has again increased to around 11 days showing a slowing down of trend of the infected persons. The overall picture shows that there have been ups and downs in the doubling time of the COVID-19 cases in Nepal and is currently around 11 days (Fig. 2).

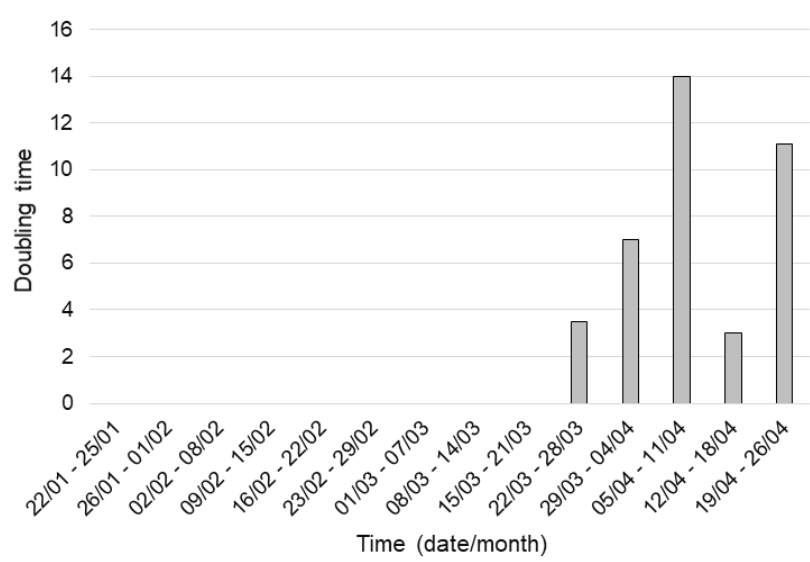

Fig. 2. Doubling time of COVID-19 cases in Nepal (Based upon weekly data analysis from $22^{\text {nd }}$ January 2020 to end of April 2020

\section{Statistical modelling of COVID-19 cases of Nepal}

The best ETS state-space model was found to be ETS (M, A, N) for the data i.e. exponential smoothing with Multiplicative Error, Additive Trend, and No Seasonality model. This is equivalent to Holt's linear additive model (Hyndman \& Athanasopolus, 2018). 


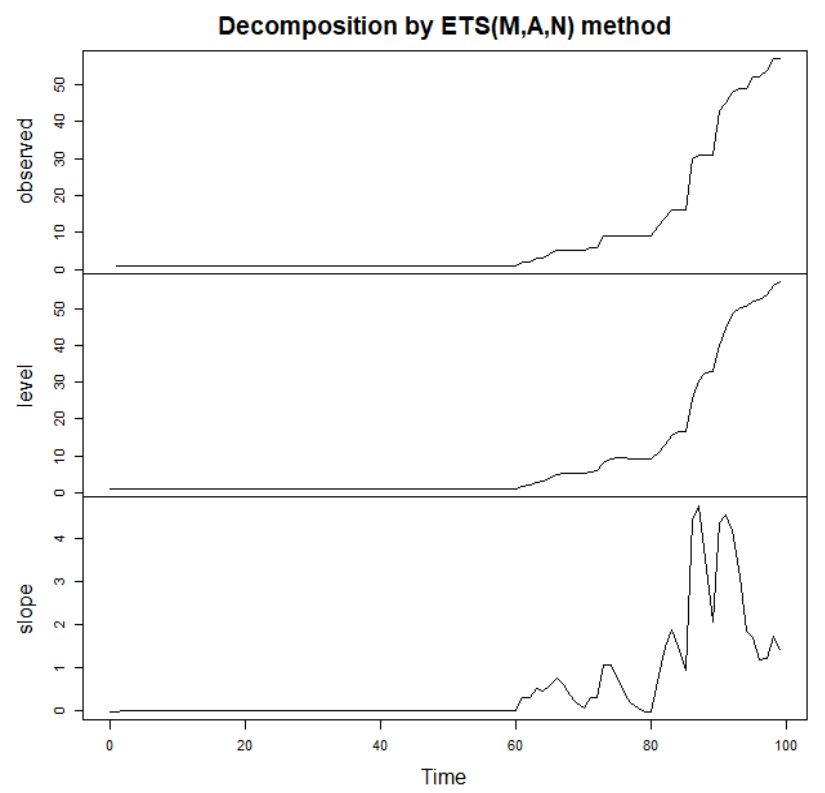

Fig. 3. ETS decomposition of cumulative COVID-19 cases of Nepal $\left(23^{\text {rd }}\right.$ January $-17^{\text {th }}$ April, 2020)

Forecasted cumulative COVID-19 cases using ETS (M, A, N) model revealed that COVID-19 cases were increasing at the rate of 2 cases per day in Nepal (Table 1). The $95 \%$ confidence interval of the forecasts was very wide, which means that standard errors are high and the precision of the estimation is low.
Thus, forecasted values may not coincide with the official reported values. The cumulative COVID cases in Nepal revealed the increasing trend of COVID-19 cases with wide variation (Fig. 4).

\section{Forecasts from ETS(M,A,N)}

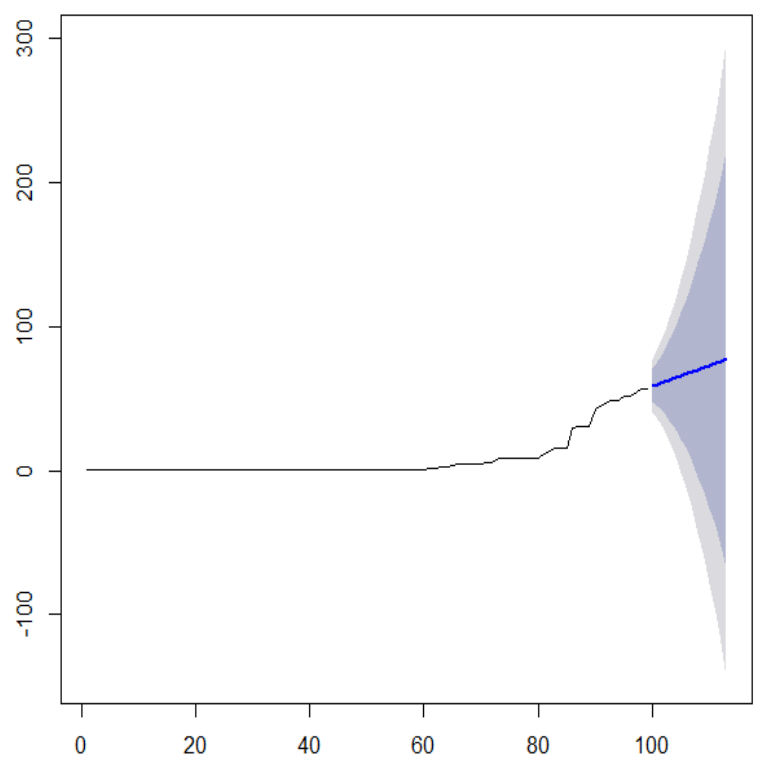

Fig. 4. Cumulative COVID-19 cases of Nepal: $2^{\text {rd }}$ January $-1^{\text {st }}$ May, 2020 using ETS $(M, A, N)$ model showing increasing trend

Table 1. Forecasted cumulative COVID-19 cases using ETS (M, A, N) model, Nepal

\begin{tabular}{lllllll}
\hline Date & Day & Forecast & Lo 80 & Hi 80 & Lo 95 & Hi 95 \\
\hline 1-May & 100 & 58.81742 & 47.318412 & 70.31643 & 41.231205 & 76.40364 \\
2-May & 101 & 60.24833 & 44.396137 & 76.10053 & 36.00449 & 84.49218 \\
3-May & 102 & 61.67925 & 40.245795 & 83.1127 & 28.89961 & 94.45889 \\
4-May & 103 & 63.11016 & 35.07717 & 91.14316 & 20.2374 & 105.98293 \\
5-May & 104 & 64.54108 & 28.996946 & 100.08521 & 10.181018 & 118.90114 \\
6-May & 105 & 65.97199 & 22.051937 & 109.89205 & -1.197936 & 133.14192 \\
7-May & 106 & 67.40291 & 14.253802 & 120.55201 & -13.881634 & 148.68745 \\
8-May & 107 & 68.83382 & 5.591121 & 132.07652 & -27.887543 & 165.55519 \\
9-May & 108 & 70.26474 & -3.964673 & 144.49415 & -43.259349 & 183.78882 \\
10-May & 109 & 71.69565 & -14.456318 & 157.84762 & -60.062415 & 203.45372 \\
11-May & 110 & 73.12657 & -25.93925 & 172.19238 & -78.381525 & 224.63466 \\
12-May & 111 & 74.55748 & -38.480945 & 187.5959 & -98.319873 & 247.43483 \\
13-May & 112 & 75.98839 & -52.160735 & 204.13752 & -119.998786 & 271.97557 \\
14-May & 113 & 77.41931 & -67.069942 & 221.90856 & -143.557931 & 298.39655 \\
\hline
\end{tabular}

Note: The negative values in the table means zero cases.

The best ARIMA model for this 99-day data of Nepal is ARIMA $(3,2,1)$. This means it required two times the difference of the series first to make the data stationary followed by a third-order autoregressive filter and firstorder moving average filter to correct the autocorrelation and forecasting error in the data. Forecasted cumulative COVID-19 cases using ARIMA $(3,2,1)$ model shows the forecasts obtained from this model for the next 14-day for Nepal (Table 2). COVID-19 cases increased at 2 cases per day in Nepal (Table 2). The $95 \%$ confidence intervals 
were found realistic. However, the forecasts may not coincide with the official reported cases.

Table 2. Forecasted cumulative COVID-19 cases using ARIMA (3,2,1) model, Nepal

\begin{tabular}{|c|c|c|c|c|c|c|}
\hline Date & Day & Forecast & Lo 80 & Hi 80 & Lo 95 & Hi 95 \\
\hline 01-May & 100 & 58.13008 & 55.92091 & 60.33926 & 54.75144 & 61.50873 \\
\hline 02-Мay & 101 & 59.77956 & 56.73407 & 62.82506 & 55.12188 & 64.43725 \\
\hline 03-May & 102 & 61.90513 & 58.17988 & 65.63039 & 56.20784 & 67.60242 \\
\hline 04-May & 103 & 62.92401 & 58.52157 & 67.32645 & 56.19105 & 69.65697 \\
\hline 05-May & 104 & 64.09565 & 58.49546 & 69.69583 & 55.53091 & 72.66038 \\
\hline 06-May & 105 & 65.56641 & 58.75999 & 72.37282 & 55.15689 & 75.97592 \\
\hline 07-May & 106 & 67.29525 & 59.33921 & 75.25128 & 55.12754 & 79.46296 \\
\hline 08-May & 107 & 68.63131 & 59.52688 & 77.73574 & 54.70728 & 82.55534 \\
\hline 09-May & 108 & 69.91791 & 59.47234 & 80.36349 & 53.94279 & 85.89304 \\
\hline 10-May & 109 & 71.3307 & 59.46664 & 83.19476 & 53.18619 & 89.47521 \\
\hline 11-May & 110 & 72.88073 & 59.58482 & 86.17663 & 52.5464 & 93.21505 \\
\hline 12-May & 111 & 74.3018 & 59.55531 & 89.0483 & 51.74899 & 96.85462 \\
\hline 13-May & 112 & 75.66426 & 59.37703 & 91.95149 & 50.75509 & 100.57344 \\
\hline 14-May & 113 & 77.06874 & 59.17249 & 94.96499 & 49.69879 & 104.43869 \\
\hline
\end{tabular}

Forecast from ARIMA $(3,2,1)$ model were lower than the official COVID-19 cases of Nepal between $1^{\text {st }}$ and $14^{\text {th }}$ May 2020 (Fig. 5). This means we need other approaches for modelling COVID-19 cases in Nepal.

Forecasts from ARIMA(3,2,1)

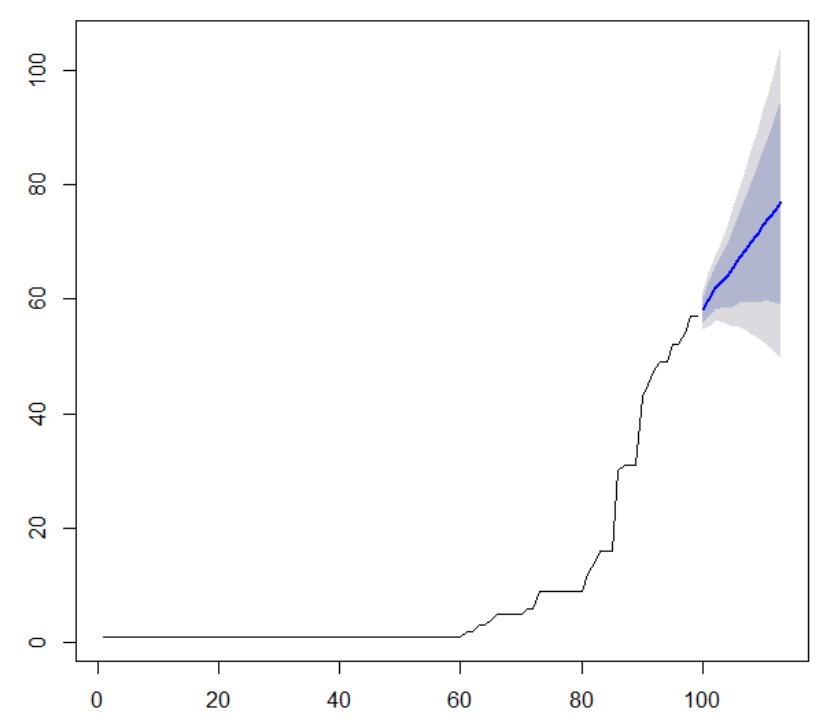

Fig. 5. Cumulative COVID-19 cases of Nepal: $23^{\text {rd }}$ January $-1^{\text {st }}$ May 2020 using ARIMA $(3,2,1)$ model showing increasing trend

Mathematical modelling of COVID-19 cases of Nepal

\section{Scenario 1}

Beta $=1 / 2=0.5$ per person; Beta $=0.5 / 29,000,000=1.72$ x $10^{-8}$ for Nepal and Gamma $=1 / 5=0.2$ (reciprocal of average incubation period of COVID-19 cases) (Fig. 6). This gave basic reproduction number (Ro) as $0.5 / 0.2=2.5$, which is the average Ro around the world (Liu et al., 2020).

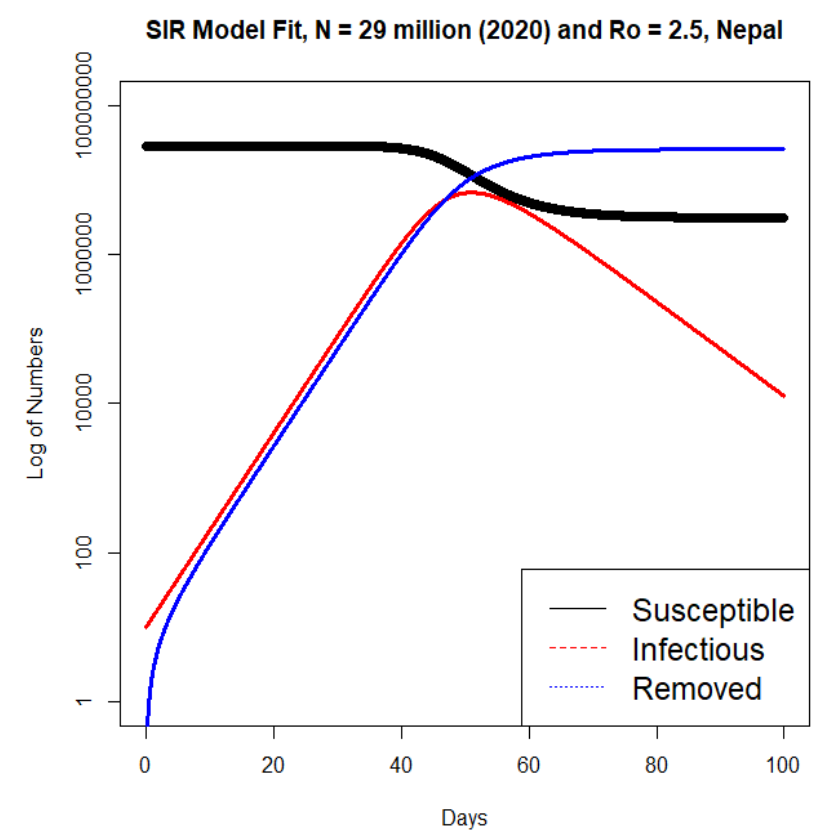

Fig. 6. SIR model with $\beta=0.5$ and $\gamma=0.2$ for $\mathrm{N}=29,000,000$ of Nepal which gave basic reproduction number $\mathrm{Ro}=\mathbf{2 . 5}$

This SIR model shows that 6770893 persons will be infected around 60 days whereas 38,560 persons will be infected at 100 days since the first case appeared in Nepal. 


\section{Scenario 2}

Beta $=1 / 5=0.2$ per person; Beta $=0.2 / 29,000,000=6.689$ x $10^{-9}$ for Nepal and Gamma $=1 / 5=0.2$ (reciprocal of average incubation period of COVID-19 cases) (Fig. 7). This gives basic reproduction number (Ro) as $0.2 / 0.2=1$.

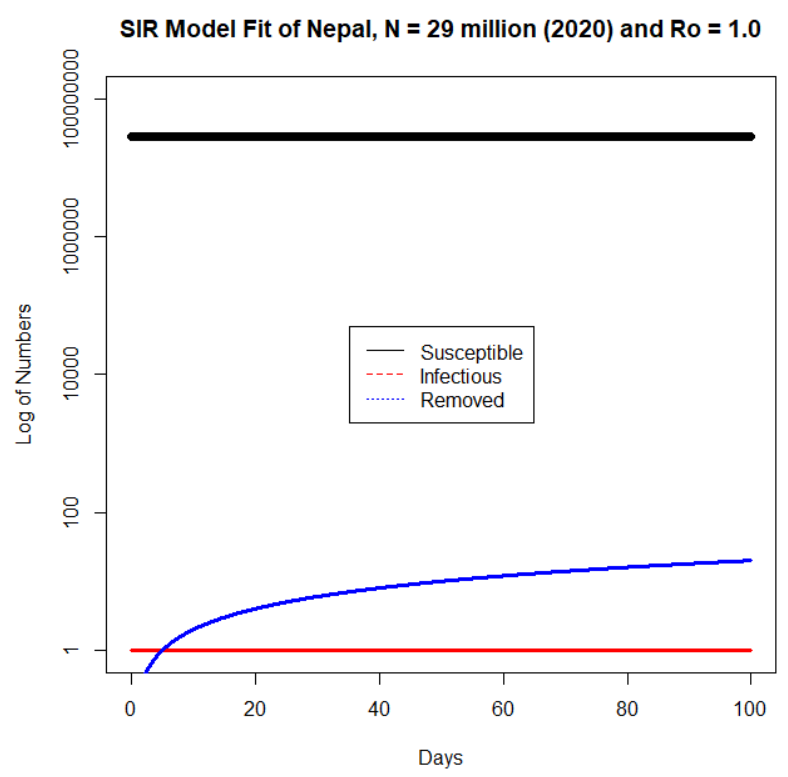

Fig. 7. SIR model with $\beta=0.5$ and $\gamma=0.5$ for $N=29,000,000$ of Nepal giving basic reproduction number $R o=1$

This SIR model shows that only 1 person will be infected each day as the basic reproduction number is 1 .

\section{Scenario 3}

We used estimated $\beta=0.5197019$ and $\gamma=0.4802873$ obtained for official cases between $23^{\text {rd }}$ January and $30^{\text {th }}$ April 2020 using LM-BFGS optimization in R software giving $\mathrm{Ro}=\beta / \gamma=1.08$. This SIR model revealed that there will be a maximum of 532,627 cases if it continues with this Ro. (Fig. 8).

Estimated $\beta$ and $\gamma$ obtained using LM-BFGS optimization in $\mathrm{R}$ software for official cases reported between $22^{\text {nd }}$ March and $30^{\text {th }}$ April 2020 were 0.5553948 and 0.4446052 respectively giving $\mathrm{Ro}=$ beta/gamma $=1.25$. This SIR model revealed that there will be a maximum of 6197014 if it continues with this Ro.

When $\mathrm{Ro}=1$ was considered for the official data on $30^{\text {th }}$ April 2020 then maximum cases will be 58.5462 and the COVID-19 epidemic will be over by June 2020 at this Ro in Nepal (Fig. 9).

SIR model based on official data revealed that COVID-19 cases will increase in Nepal with Ro of 1.08 and the epidemic will be over only by December 2020 with a peak of cases on August 2020 for this Ro. On the other hand, the COVID-19 epidemic will only be over around one year time if Ro continues as 1.25.
Infected in Nepal (SIR Model Fit)

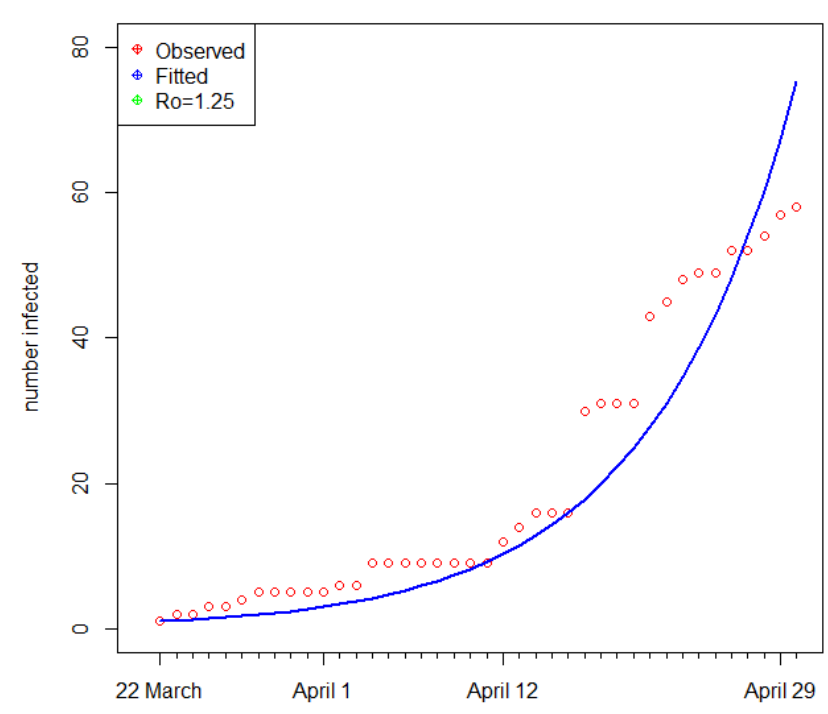

Fig. 8. SIR model with official cumulative COVID-19 cases of Nepal if $R o=1.25$

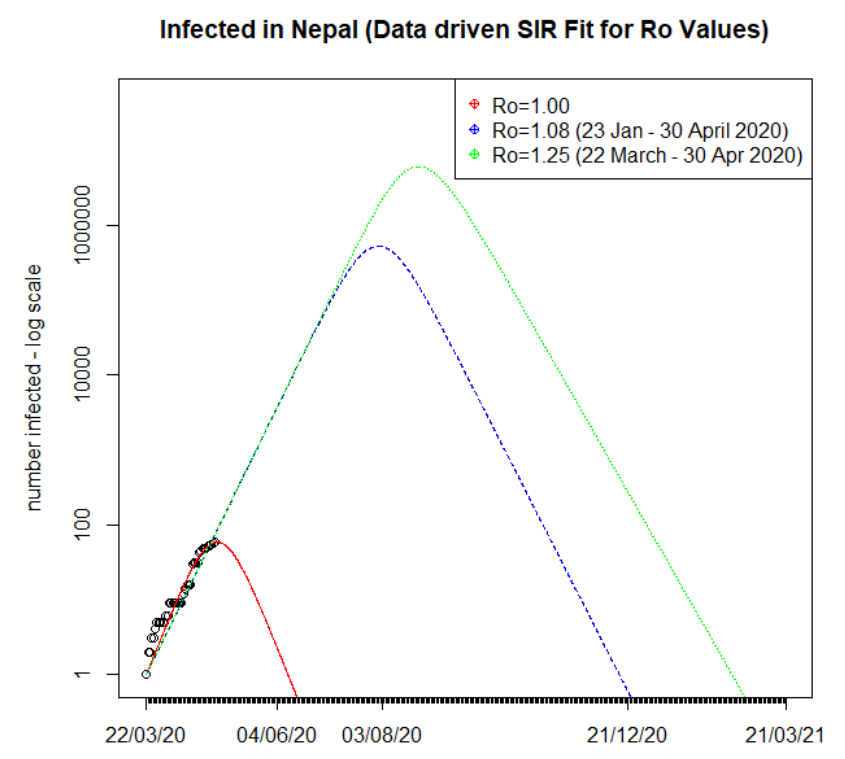

Fig. 9. Data-driven SIR model fit with three Ro values (1, 1.08, and 1.25) for Nepal

SIR model based on official data revealed that COVID-19 cases will increase in Nepal with Ro of 1.08 and the epidemic will be over only by December 2020 with a peak of cases on August 2020 for this Ro. On the other hand, the COVID-19 epidemic will only be over around one year time if Ro continues as 1.25.

\section{DISCUSSION}

The analysis of COVID-19 cases in Nepal provided an insight into the situation till the implementation of the first phase of lockdown and prediction of the expected 
scenario thereafter. The data of the cases were based on the results of the test confirmed by RT-PCR. From the trend graph of cases as percent of RT-PCR tests, the percent of cases have rapidly decreased as the number of tests increased in the month of February and has remained more or less constant between 0.2 to $0.5 \%$ thereafter. This is an indication of an absence of a significant rise in COVID-19 cases despite the increase in the tests substantially in the months of March-April in Nepal, although the number of tests may still not be sufficient to cover a large proportion of the population in Nepal. The overall growth of COVID-19 cases in Nepal is not high, which can be taken positively and credited to the lockdown implemented by the Nepal Government and awareness of the diseases through media along with the preventive measures. The doubling time of COVID-19 cases along with the incubation period of the coronavirus are important variables in the spread of the epidemic. The incubation period of the virus has been reported with a certain amount of variability (2-14 days) with the median average hovering around 5 days with possible outliers up to 27 days (Worldometer, 2020).

The overall picture shows that there has been ups and downs in the doubling time of the COVID-19 cases in Nepal and is currently around 11 days (Fig. 1) which is just above 10 days doubling time of COVID-19 cases in India as reported by different news channels of India though the total cases in Nepal are still negligible compared to that of India. Bhandary (2020) has stated that with implementation of lockdown the doubling time increased from 5 days to 15 days.

Statistical modelling showed that COVID-19 cases may continue to increase exponentially in Nepal. Forecasts from the best ARIMA model (MAPE $=4.18$ ) are found to be more precise than the ETS exponential smoothing model (MAPE $=4.55)$. Forecasts from the best ARIMA model will be a valid estimate if clusters with more than 10 cases will be found there in the future too. This has already happened once between $18^{\text {th }}$ April and $1^{\text {st }}$ May 2020 in Nepal and thus requires particular attention of the concerned administrators and policymakers. However, it will not be valid if the cases will be increased at higher rates in the country. ETS and ARIMA models produced estimated values of COVID-19 cases for Nepal based upon the currently available official data. Despite the possibility of questions on whether sufficient tests have been conducted for such modelling, COVID-19 cases in Nepal have not risen sharply in high numbers and the total cases in Nepal are still below 100 but expected to rise in coming days.

Compartmental SIR model on the other hand reveals that nearly seven million Nepalese population might be infected with an average global basic reproduction number of 2.5 for COVID-19 cases and maximum cases would have reached within 60 days of the first case, which fortunately did not happen in the country. The total number of cases would have been only 1 if the basic reproduction number remained at one in Nepal, which also did not happen as 30 cases were reported by $17^{\text {th }}$ April 2020 and 58 in $30^{\text {th }}$ April 2020.

The basic reproduction number of Nepal was computed as 1.08 for $23^{\text {rd }}$ Jan $-30^{\text {th }}$ April 2020 period, which means lockdown was working well to maintain a low level of basic reproduction number in the country. Further, it also revealed that COVID-19 will only be over by December 2020 with peak cases in August 2020 with Ro of 1.08. On the other hand, basic reproduction number of 1.25 was computed for total cases reported from $22^{\text {nd }}$ March to $30^{\text {th }}$ April 2020 period, which means that COVID-19 did not increase exponentially but it will remain for at least a year in the country. Thus, these results suggest to continue the lockdown in the hotspots (heavily affected areas), and slowly open the lockdown on the least affected areas with social/physical distancing and personal hygiene maintenance in Nepal.

This analysis we performed have been restricted to the lockdown implemented from $24^{\text {th }}$ March 2020 till the end of April 2020 and not a final assessment yet considering that the spread of disease could still be at the early stage in Nepal and calls for re-assessments periodically in future as well till the pandemic phases out.

\section{CONCLUSIONS}

The data-based trends for the COVID-19 epidemic in Nepal have been analyzed followed by the assessment of the outbreak impacts in comparison with existing models. The outcomes of the research can be summarized as follows:

1. The total COVID-19 cases are increasing by following the logistic curve. However, there has been a variation in the doubling time during the analysis period, which can be attributed to the effect of lockdown imposed by the Government. The forecasts from the best ARIMA model may provide more precise and valid estimates if clusters with more than 10 cases are found in the future.

2. As in the compartmental SIR model, nearly 7 million people might get infected. With an average global basic reproduction number of 2.5 for COVID-19 cases, maximum cases would have reached within 65 days, which fortunately did not happen in the country. The basic reproduction number in Nepal being maintained at a low level of 1.08 for the period between $23^{\text {rd }}$ January and $30^{\text {th }}$ April 2020 is an indication of the effectiveness of the lockdown in containing the COVID-19 spread.

3. Further, the model has suggested that the COVID-19 will extend to December 2020 with the peak cases in 
Trend analysis, modelling and impact assessment of COVIS-19 in Nepal

August 2020. On the other hand, basic reproduction number of 1.25 was computed for total cases reported for the $22^{\text {nd }}$ March $-30^{\text {th }}$ April 2020 period, which implies that COVID-19 may persist at least for a year in the country.

Thus, the results so far obtained clearly recommend continuing the lockdown in the hotspots (heavily affected areas) and gradually easing the lockdown in the least affected areas with strict social/physical distancing and personal hygiene maintenance.

\section{ACKNOWLEDGEMENTS}

We are thankful to Prof Dr. Dinesh Raj Bhuju, Academician, Nepal Academy of Science and Technology for his encouragement. We acknowledge the Ministry of Health and Population, Nepal Government for the data on COVID-19.

\section{REFERENCES}

Bastola, A., Sah, R., Rodriguez-Morales, A. J., Lal, B. K., Jha, R., Ojha, H. C., Shrestha, B., Chu, D. K. W., Poon, L.L.M., Costello, A., Morita, K., \& Pandey, B. D. (2020). The first 2019 novel coronavirus case in Nepal. Lancet Infectious Disease, 20(3), 279-280.

Bhandary, S. (2020). Effectiveness of lockdown as COVID-19 intervention: Official and computed cases in Nepal. Journal of Patan Academy of Health Sciences, 7(1), 37-41.

Hyndman, R., \& Athanasopoulos, G. (2018). Forecasting: principles and practice $\left(2^{\text {nd }}\right.$ ed.). In OTexts, Melbourne, Australia.

Hyndman, R., Athanasopoulos, G., Caceres, G., Chhay, L., O'Hara-Wild, M., Petropoulos, F., et al. (2020). Package forecast: Forecasting functions for time series and linear models. Available from: https://github.com/robjhyndman/forecast.

Liu, Y., Gayle, A.A., Wilder-Smith, A., \& Rocklov, J. (2020). The reproductive number of COVID-19 is higher compared to SARS coronavirus. Journal of Travel Medicine, 27(2), 21. https://doi.org/10.1093/jtm/taaa021

MoHP. (2020). Coronavirus disease (COVID-19) outbreak updates and resource material. Health Emergency and Disaster Management Unit, Health Emergency Operation Center, Ministry of Health and Population, Nepal. Available from: https://heoc.mohp.gov.np/update-on-novel-coronavirus-COVID-19.

Paudel, S., Dangal, G., Chalise, A., Bhandari, T.R., \& Dangal, O. (2020). The coronavirus pandemic: What does the evidence show? Journal of Nepal Health Research Council, 18(1), 1-9.

Pun, S.B., Mandal, S., Bhandari, L., Jha, S., Rajbhandari, S., Mishra, A.K., Chalise, B.S., \& Shah, R. (2020). Understanding COVID-19 in Nepal. Journal of Nepal Health Research Council, 18(1), 126-127.

Soetaert, K., Petzoldt, T., \& Setzer, R.W. (2010). Solving differential equations in R: package deSolve. Journal of Statistical Software, 33(9):1-25.

WHO. (2020a). Naming the coronavirus disease (COVID19) and the virus that causes it. Available from: https://www.who.int/emergencies/diseases/novelcoronavirus-2019/technical-guidance/naming-thecoronavirus-disease-(covid-2019)-and-the-virusthat-causes-it.

WHO. (2020b). Coronavirus disease 2019 (COVID-19), Situation Report-101. Available from: https://www.who.int/docs/defaultsource/coronaviruse/situation-reports/20200430sitrep-101-covid-19.pdf?sfvrsn=2ba4e093 2 .

WHO. (2020c). Rolling updates on coronavirus disease (COVID-19). Available from: https://www.who.int/emergencies/diseases/novelcoronavirus-2019/events-as-they-happen.

Worldometer. (2020). Available from: https://www.worldometers.info/coronavirus/coronav irus-incubation-period/

Wu, Y.C., Chen, C.S., \& Chan, Y.J. (2020). The outbreak of COVID-19: An overview. Journal of Chinese Medical Association, 83(3), 217-220.

Yip, C.C., Ho, C.C., Chan, J.F., To, K.K., Chan, H.S., Wong, S.C., Leung, K., Fung, A.Y., Ng. A.C., Zou, Z., Tam, A.R., Chung, T.W., Chan, K., Hung, I.F., Cheng, V.C., Tsang, O.T., Tsui, S.K., \& Yuen, K. (2020). Development of a novel, genome subtraction-derived, SARS-CoV-2-specific COVID19-nsp2 real-time RT-PCR assay and its evaluation using clinical specimens. International Journal of Molecular Science, 21(7), e2574. https://doi.org/10.3390/ijms21072574 